\section{Christer CARLSSON}

Department of Business Administration, Ảbo Academy, 20500 A bo 50, Finland

\section{On fuzzy sets}

As the contributions to this section of HSM are not very numerous I have found it necessary to generate some news of my own. Besides informing you about coming events, I will also put forward some concerns regarding present attitudes towards the theory of fuzzy sets and its applicability in management-oriented fields of research.

Let us take as 'management-oriented fields of research' those labeled as behavioral science, cybernetics, decision theory, human systems management, management science, MCDM, operational research, probability theory, general systems research, utility theory - what a variety of scientific endeavours aimed at functions any normally gifted and/or successful manager describes as mostly based on intuition, personality, experience and common sense. Into this jungle entered the theory of fuzzy sets in the early 70 s with the fairly modest claim to be a way for handling imprecision, because - it also claimed - probability theory is no good for that purpose (see Bellman-Zadeh [3, B-141]):

"Much of the decision-making in the real world takes place in an environment in which the goals, the constraints and the consequences of possible actions are not known precisely. To deal quantitatively with imprecision, we usually employ the concepts and techniques of probability theory and, more particularly, the tools provided by decision theory, control theory and information theory. In so doing, we are tacitly accepting the premise that imprecision - whatever its nature - can be equated with randomness. This, in our view, is a questionable assumption.

North-Holland Publishing Company

Human Systems Management 3 (1982) 212-214
Let me now assume that most HSM-readers have some notion of what is meant by fuzzy sets. I suspect - please write to me if I am doing you wrong - that this notion is the common belief that fuzzy sets represents a bunch of mathematically advanced tools, techniques and methods for handling imprecision in an utterly complex and precise (!) way. This notion is described by the sarcastic observation that "there is nothing fuzzy about the theory of fuzzy sets", and the conjecture that one should not use precise tools for handling imprecision. In other words, that the theory of fuzzy sets, by becoming a well-developed field of research, and by developing a conceptual framework and a mathematical apparatus of its own, has disqualified itself from dealing with imprecision in a relevant way.

Regarding impression there seems to be a dominating dogma that imprecision (or ambiguity, or uncertainty, or vagueness) can be conveyed only through concepts which are in themselves imprecise. Obviously this is a heresy.

In a management context there seem to be two different reasons for imprecision:

(i) lack of knowledge, and

(ii) excessive knowledge.

The imprecision can be on the part of a decision maker or in the models (methods, techniques, tools) he applies as decision aids; in case (i) imprecision allows a decision maker to consider several alternatives simultaneously, and to commmunicate that fact to other decision makers; in case (ii) imprecision offers simplification in the sense that a generalized (imprecise) concept represents an array of detailed concepts. Clearly the mean - which is a case (ii)-concept - is less precise than a set of detailed observations from which it is calculated, but as a concept the mean is well defined and precise. The same holds for the fuzzy concept 'tall', as soon as the corresponding membership function is defined. Also in case (i) the imprecision may be a well-defined concept: it may be purposeful to recognize that 'tall' applies to various length, and this concept is well defined as long as there is a finite set of alternatives for which a membership function can be defined. 
As a consequence, there is nothing wrong in introducing imprecision through precise concepts, and that should not be a point advanced against the theory of fuzzy sets. But there is another observation to be made, and it is my belief that it is based on a mythology: "the body of primitive people's beliefs concerning its origin, early history, heroes, deities and so forth, as distinguished from the true accounts which it invents later" (Devil's Dictionary). The mythology is that fuzzy set theory is identified with those parts of it which are of no immediate relevance for a management context: fuzzy predicate calculus, fuzzy algebra, fuzzy topology, fuzzy logic, fuzzy integrals, etc. This mythology seems to be promoted by those with a superficial knowledge of only parts of the fuzzy sets theory - parts which are irrelevant for a management context. Fuzzy mathematics should, of course, be recognized as a field in its own right.

Another, more critical, point concerns the fact that the tools developed for carrying out the intentions behind the theory of fuzzy sets are not too well suited for that purpose. The so-called min-operator has been shown to be of limited applicability for fuzzy decisions; there is no methodology developed for constructing and validating membership functions; there are very few purely fuzzy models - most fuzzy models are only 'fuzzifications' of traditional OR- and MS-models. These shortcomings are, however, not eliminated by pointing out that fuzzy topology is of no immediate use in a management context - one should instead find out how existing tools could be developed to serve the purposes of the theory in a more efficient way. It is no good to accuse mathematicians of being mathematicians, one should accuse management scientists of being conservative and shallow-minded.

These, I think, are the reasons for rather a negative attitude towards the theory of fuzzy sets among our colleagues in management-oriented fields of research.

Then - in order to take a less defensive approach - let us find out what fuzzy sets has to offer us (cf. [4]): the theory promises that we would be able to structure and describe activities and observations, which differ from each other only vaguely, to formulate them in models and to use these models for various purposes - such as problem-solving and decision-making. This is an ability we already have as human beings, but which is not present in classical mathematics and not - as a consequence - in any science-oriented methodology. As scientists we are trained to use precise concepts and sharp definitions in order to be able to build precise and elegant models, to use mathematically well-defined algorithms so that we will be able to give distinct descriptions, precise explanations and concise predictions. The point is, as demonstrated by the recent criticism of operations research methodology (cf. [1,2]) that this ability is not the most important one for handling managerial problems.

(Fuzziness: a multitude of relatively unknown possibilities, which should not be described in terms of probability theory; Devil's Dictionary, had it been published after 1965, and not already in 1906.)

\section{References}

[1] R.L. Ackoff, The future of operational research is past, $J$. Operational Res. Soc. 30 (2) (1979).

[2] R.L. Ackoff, Resurrecting the future of operational research, J. Operational Res. Soc. 30 (3) (1979).

[3] R.E. Bellman and L.A. Zadeh, Decision-making in a fuzzy environment, Management Sci. 17 (4) (1970).

[4] C. Carlsson, On the relevance of fuzzy sets in management science methodology, in: B.G. Gaines, L.A. Zadeh and H.J. Zimmermann, Eds., Decision Analysis and Fuzzy Sets, TIMS Studies in Management Sciences (North-Holland, Amsterdam) to appear.

\section{Meeting Announcements and Calls for Papers}

* Seventh Symposium on Operations Research, St. Gall, Switzerland, August 19-21, 1982.
Addresses: Prof. Dr. H. Loeffel and Dr. P. Stahly, Institut für Unternehmensforschung, 
Hochschule St. Gallen, Bodanstrasse 6, CH-9000 St. Gallen, Switzerland

* XI International Symposium on Mathematical Programming, Bonn, West Germany, August 23-27, 1982. The triennal scientific meeting of the Mathematical Programming Society, held at the University of Bonn. Address: Mathematical Programming Secretariat, c/o Institut für Operations Research, Hassenstrasse 2, D-5300 Bonn 1, West Germany

* Symposium on Production Management, EIASM, Brussels, Belgium, March 7-9, 1983. Address: Dr. J.M. Proth, INRIA, B.P. 105, F78153 Le Chesnay Cedex, France

* 3rd IFAC/IFORS Symposium on Large Scale Systems: Theory and Applications, Warsaw, Poland, July 11-15, 1983. Address: Dr. Z. Nahorska, 3rd IFAC/IFORS LSSTA, Systems Research Institute, Polish Academy of Sciences, ul. Newelska 6, 01-447 Warszawa, Poland
* IFAC Symposium on Fuzzy Information, Knowledge Representation and Decision Analysis, Marseille, France, July 19-21, 1983. 200-300 word abstract should be sent by June, 1982; full papers by September, 1982. Address: IFAC Symposium, Laboratoire de Biomathematiques, Faculté de Médecine, 27 boulevard Jean-Moulin, F-13 385 Marseille Cedex 5, France

* EURO VI, Vienna, Austria, July 19-22, 1983. The theme of this conference is "Operational Research and Decision Support". Deadline for submission of 200 word abstracts is October 1, 1982. Address: EURO VI, c/o Interconvention, P.O. Box 80, A-1 107 Vienna, Austria

* 11 th IFIP Conference on System Modelling and Optimization, Copenhagen, Denmark, July 2524, 1983. Address: Prof. P. Thoft-Christensen, Aalborg University Center, Inst. of Building Technology and Structural Engineering, P.O. Box 159 DK-9100 Aalborg, Denmark 